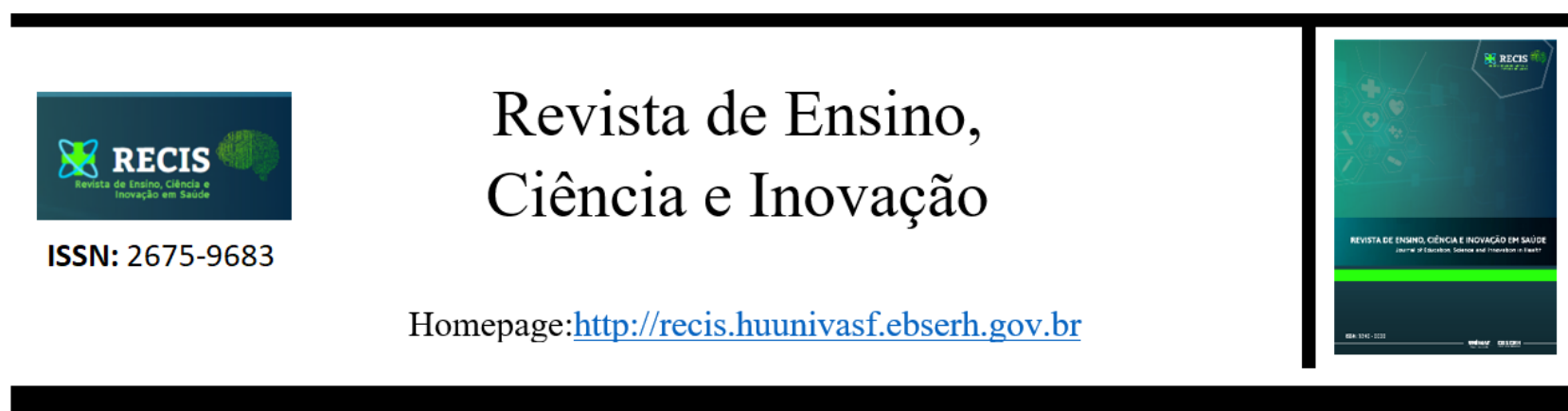

\title{
Perfil das infecções hospitalares em um Hospital Universitário do Submédio do Vale do São Francisco - Brasil
}

\section{Profile of nosocomial infections in a University Hospital of the sub-valley of Vale do São Francisco - Brazil}

\section{Ana Tânia Pereira Dias'; ; Stefane Amorim Melo'; Michelle Machado Rigo²; Daniel Gomes de Souza $^{3}$; Daniely da Silva Figueiredo ${ }^{3}$; Rafaella Ayanne Alves dos Santos ${ }^{3}$; Carine Freitas e Silva $^{4}$, Aline Vitória de Oliveira ${ }^{5}$, Carine Rosa Naue $^{3}$}

${ }^{1}$ Discente de Medicina da Faculdade Estácio de Juazeiro - BA, ${ }^{2}$ Professora de Medicina da Faculdade Estácio de Juazeiro - BA, ${ }^{3}$ Hospital Universitário da UNIVASF/EBSERH, ${ }^{4}$ Discente da Faculdade UniBRAS Juazeiro, ${ }^{5}$ Centro Universitário Barão de Mauá

E-mail para contato: anatania21@hotmail.com

Artigo recebido em 08/02/2021 e aceito em 20/04/2021

\begin{abstract}
RESUMO
As Infecções Hospitalares (IH) causam um alto impacto nos indicadores de morbimortalidade, aumentam o período de internação e elevam os custos para o governo. O presente estudo analisou o perfil das infecções hospitalares de um Hospital Universitário. Trata-se de um estudo observacional, retrospectivo e descritivo com uma abordagem quantitativa, cuja fonte dos dados foi o relatório bienal do Sistema de Controle de Infecção Hospitalar durante os anos de 2016 e 2017. Foram calculadas a taxa geral de IH, a porcentagem de Infecções de Sítio Cirúrgico (ISC), a densidade de incidência (DI) das infecções de pneumonia associada a ventilação mecânica (PAV), das Infecções do Trato Urinário (ITU) e das Infecções Primária da Corrente Sanguínea (IPCS). Foi observado uma taxa geral de IH nos anos 2016 e 2017 que variou entre 5 e 11,8\%. A taxa de ISC, no ano de 2016, teve uma média de 2,5\%, porém, percebe-se um aumento considerável em 2017, com uma taxa máxima de 5,9\%. Para a PAV, a DI durante o ano de 2016 variou entre $12,9 \%$ a $68,8 \%$, já em 2017, a variação foi entre 23,1 e $90 \%$. Em relação a ITU, em 2016, a DI foi 33\%, ao passo que em 2017 foi de 28,3\%. Para as IPCS, no ano de 2016 a DI máxima foi 55,8\%, enquanto em 2017, foi de 27,2\%. Para as IH, a prevenção é uma ferramenta essencial. A sensibilização da equipe de saúde, visitantes e familiares quanto as melhores práticas é fundamental para a redução dos índices das IH.
\end{abstract}

Palavras-chave: Controle de Infecções. Hospital. Taxas.

\begin{abstract}
The hospital-acquired infections (henceforth HI) have a high impact on the morbidity and mortality indicators, increase the hospitalization of patients and consequently raise the costs of the government. This study analysed the profile of the hospital-acquired infections from a university hospital. Is na observational, retrospective, and descriptive study with a quantitative approach, whose dataset were extracted by the biennial report of the Hospital Infection Control System from 2016 to 2017. The overall HI rate, the percentage of the surgical site infections (SSIs), the incidence density (ID) of the infections associated to the Ventilator-Associated Pneumonia (VAP), urinary tract infections (UTIs), and primary bloodstream infections (BSIs) were calculated. In the overall $\mathrm{HI}$ rate, there was a variation between $5 \%$ and $11,8 \%$ in 2016 and 2017. The SSI in 2016 had an average of 2,5\%, but in 2017 there was an increase, with a maximum rate of $5.9 \%$. The VAP in 2016 the ID ranged from $12.9 \%$ to $68.8 \%$, and in 2017 the variation was between 23.1 and $90 \%$.
\end{abstract}


Regarding the UTI, in 2016, the DI was 33\%, while in 2017 it was $28.3 \%$. For BSIs, in 2016 the maximum DI was $55.8 \%$, while in 2017 , it was $27.2 \%$. The conclusions show that HI prevention becomes an essential tool. Raising awareness among the health team, visitors and family members about the best practices is essential to reduce $\mathrm{IH}$ indexes.

Keywords: Infection Control. Hospital. Rote.

\section{INTRODUÇÃO}

O termo infecções hospitalar, na década de 1990, foi substituído por Infecção Relacionada a Assistência à Saúde (IRAS), sendo uma designação conceitual mais ampla que abrange as infecções adquiridas e relacionadas a assistência à saúde em qualquer ambiente. Portanto, a definição para IRAS é aquela infecção adquirida após a admissão do paciente e que se manifesta durante a internação ou a alta hospitalar, quando puder ser relacionada com a internação ou procedimentos hospitalares. Cabendo ainda dentro dessa definição, mencionar que são infecções que se manifestam após 72 horas da internação, quando associadas aos procedimentos diagnósticos e/ou terapêuticos, realizados durante este período. ${ }^{1}$ Essas infecções têm se tornado cada vez mais presente no âmbito da saúde. Isso porque abrange não somente infecções adquiridas em ambiente hospitalar, mas também, em outros locais que se presta assistência médica, como ambulatórios, domicílios, dentre outros. Alguns fatores como a precária higienização das mãos, a má desinfecção de superfícies e equipamentos das instituições, além da virulência da cepa bacteriana, também contribuem para esse feito. ${ }^{2-4}$

Nesse contexto, as IRAS têm se tornado assunto de relevância pública, devido ao alto impacto nos indicadores de morbimortalidade, atrelados à longa permanência dos pacientes nos serviços de saúde e à consequente elevação de custos para o governo, representando cerca de 20 a $30 \%$ dos desfechos em unidades de saúde. ${ }^{5}$

Em nível mundial, cerca de 1,4 milhões de pessoas adquirem IRAS, e segundo dados publicados em estudo desenvolvido por Catão e colaboradores $^{6}$, estima-se que são internadas, anualmente, nos Estados Unidos da América (EUA), cerca de 40 milhões de pessoas, sendo 2 milhões diagnosticadas com algum tipo de IRA, perfazendo 88 mil mortes ao ano.

No Brasil, os dados sobre tais infecções ainda são escassos e pouco disseminados, no entanto, de acordo com inúmeros estudos publicados, as taxas podem variar, dependendo da natureza do serviço (público ou privado), especialidade, tempo de permanência, perfil de pacientes e por fim, dos tipos de ambiente hospitalar, sendo as Unidades de Terapia Intensiva (UTI's) líderes nesse ranking. ${ }^{7}$

As UTI's são ambientes especializados e complexos que diariamente recebem pacientes com perfis variados e problemas de saúde distintos. Nesse sentido, a incidência de infecção hospitalar depende de inúmeros fatores individuais como, idade, estado nutricional, comprometimento imunológico e gravidade da doença, associados às características próprias do ambiente de terapia intensiva. Além disso, têm-se ainda a realização de procedimentos invasivos, em conjunto com o uso indiscriminado de antimicrobianos e imunossupressores. ${ }^{7,8}$

Diante do exposto é preciso levar em consideração os principais tipos de Infecções Relacionadas a Assistência em Saúde (IRAS), ressaltando-se as mais prevalentes, como as Infecções de Corrente Sanguínea (ICS's), provenientes do uso prolongado de cateteres venosos ou arteriais, que são inseridos com o objetivo de realizar administração de fluídos, eletrólitos, medicações, nutrição parenteral e hemoderivados. ${ }^{9}$ Outro tipo muito frequente refere-se às Infecções do Trato Urinário (ITU's), associadas ao tempo de permanência do cateter vesical, além das infecções respiratórias secundárias ao uso da ventilação mecânica.

Essas infecções são causadas, em sua maioria, por bactérias e dependendo do setor ou do serviço no ambiente hospitalar, uma predomina em detrimento de outras. Entre as bactérias causadoras de infecção em hospitais, destacam-se no grupo das Gram positivas os Staphylococcus aureus, os Enterococcus e os Staphylococcus coagulase-negativa (SCN) podendo apresentar diferentes perfis de resistência. ${ }^{10,11}$

Entre os bacilos Gram negativos (BGN), ganham destaque: Escherichia coli, Klebsiella pneumoniae, Pseudomonas aeruginosa e Acinetobacter baumanni, todos com diferentes mecanismos de resistência. ${ }^{12,13}$

Diante da relevância dessa temática, sobretudo em busca de meios profiláticos das infecções hospitalares, o presente estudo objetivou analisar o perfil das infecções hospitalares em um 
Hospital Universitário do Submédio do Vale do São Francisco.

\section{MATERIAL E MÉTODOS}

A pesquisa trata-se de um estudo observacional, retrospectivo e descritivo com abordagem quantitativa, cujas fontes dos dados para a pesquisa foi o relatório bienal do Sistema de Controle de Infecção Hospitalar (SCIH) do ano de 2016 e 2017 do Hospital Universitário.

O Hospital apresenta perfil assistencial de hospital geral de média e alta complexidade à comunidade adulta, com dimensionamento dos serviços assistenciais de ensino e pesquisa. É considerado referência em traumas, politraumas, ortopedia, neurocirurgia, clínica geral e médica. A instituição conta com um número de 129 leitos, sendo 111 destinados ao internamento de pacientes clínicos e cirúrgicos e 18 de terapia intensiva. Sendo 37 leitos destinados a especialidade traumato-ortopedia.

Para realização da pesquisa, a amostra foi constituída de 689 pessoas no ano de 2016 e 694 no ano de 2017, em que todos foram classificados como pacientes que adquiriram IRAS. Para diagnóstico das IRAS foram utilizados os critérios estabelecidos pelo Ministério da Saúde/ANVISA Critérios Diagnósticos de Infecções Relacionadas à Assistência à Saúde de 2013 e 2017 $7^{14}$. Foram considerados como critérios de inclusão: pacientes internados no hospital nos períodos estabelecidos e que apresentaram sinais sugestivos de infecção hospitalar com resultado positivo para cultura e clínica favorável.

A Taxa Geral de Infecção Hospitalar foi calculada através do número total de infecções classificadas pelos critérios diagnósticos estabelecidos pela Anvisa pelo número total de saídas do hospital. As infecções de sítio cirúrgico (ISC) foram calculadas pela quantidade de ISC pelo número total de cirurgias limpas realizadas. A densidade de incidência das infecções de pneumonia associada a ventilação mecânica (PAV) foram calculadas através do número de casos novos de PAV no período do estudo pelo número de pacientes em ventilação mecânica-dia no período do estudo. A densidade de incidência das infecções do trato urinário (ITU) foi calculada através do número de Infecções do Trato Urinário associadas ao uso do cateter vesical de demora no período do estudo. A densidade da infecção primária da corrente sanguínea foi calculada através do número absoluto de Infecções
Primárias de Corrente Sanguínea (IPCS) identificadas pelo número de pacientes com cateter-dia durante o período do estudo.

A taxa geral de infecções hospitalares assim como a taxa das infecções de sítio cirúrgico foi calculada utilizando dados do Hospital Inteiro (contemplando todos os setores de internamento). Em relação as infecções do trato urinário, infecções associadas a ventilação mecânica e infecções de corrente sanguínea foram estudas somente do setor da UTI.

As identificações dos micro-organismos foram realizadas através de culturas representativa da topografia das infecções que estavam anexadas aos prontuários, juntamente com outros dados importantes. Foram coletados dados referentes aos procedimentos invasivos, tempo de duração do procedimento, condição clínica do paciente, tipo de micro-organismo isolado, problemas médicos pré-existentes, a necessidade de consulta de serviço, a necessidade de incisão e drenagem, evento incitante e tipo de infecção.

\section{RESULTADOS}

Ao longo do ano de 2016 foi observado que a taxa geral de IRAS do Hospital oscilou, ficando entre $5,7 \%$ e $11,8 \%$ no ano de 2016 e entre 5\% e 10,7\% no ano de 2017 (Figura 1).

A taxa geral máxima de Infecção Hospitalar é estimada em torno de 5\% como referência universal nos serviços de saúde, podendo oscilar a depender do perfil da unidade hospitalar. No presente Hospital, devido ao alto grau de complexidade cirúrgica ortopédica e traumas e/ou violência externa não se enquadrou nesta estimativa para taxa geral de infecção, uma vez que as médias de 8,45\% nos anos de 2016 e 2017.

No decorrer do ano de 2016, no período entre maio e julho a taxa superou os $10 \%$, porém, devido as intervenções realizadas nos meses de agosto a dezembro a taxa foi reduzida e conseguiu-se fixar em torno de $6 \%$ a $8 \%$. Isso ocorreu devido a revisão do processo de trabalho, a partir da coleta de dados, acompanhamento e fechamento dos casos de infecção hospitalar individualizado.

Em relação a porcentagem de infecções de sítio cirúrgico observa-se (Figura 2) o crescimento na taxa de infecção de sítio nos últimos meses do ano de 2016, registrando um pico em novembro com $4,6 \%$. 


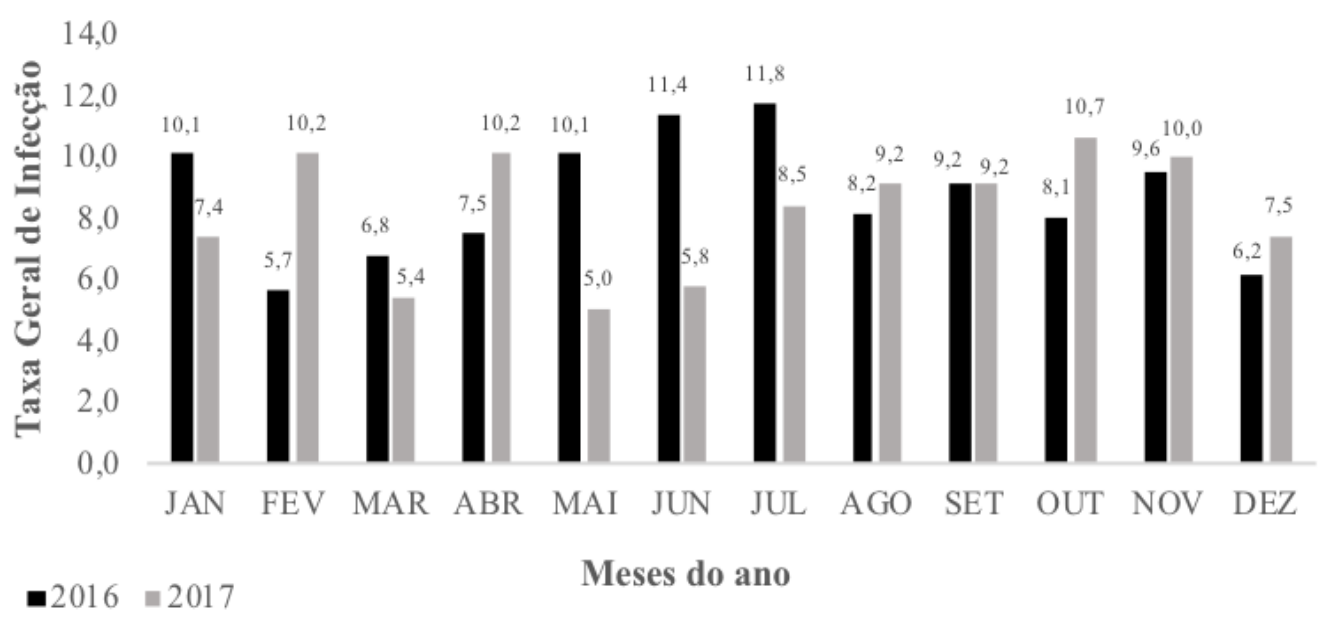

Figura 01 - Taxa Geral de Infecções Relacionadas à Assistência à Saúde do Hospital Universitário no ano de 2016 e 2017.

Apesar de manter-se abaixo da meta pactuada, com uma taxa média de $2,5 \%$, esse indicador necessitou de uma atenção especial, para frear o crescimento iminente. Já em 2017 percebe-se um aumento considerável das ISC no mês de fevereiro, com uma taxa de 5,90\%, no entanto, houve uma queda considerável após e só no mês de julho novo aumento atingindo $4,8 \%$ (Figura 2).

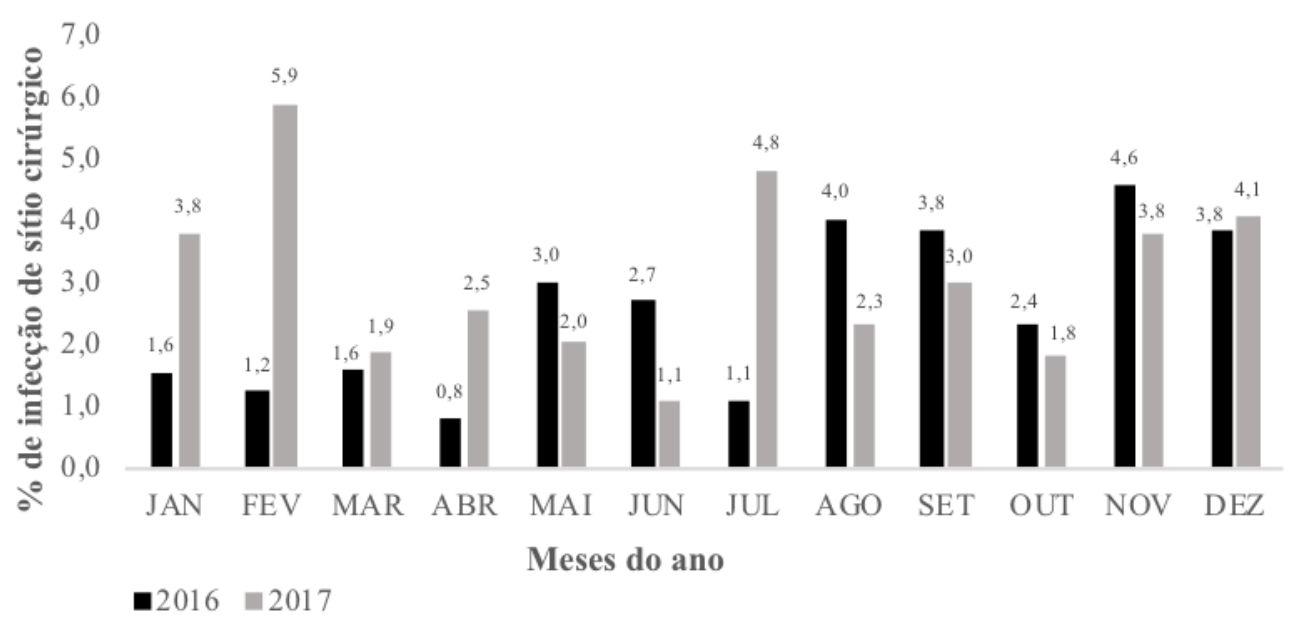

Figura 02 - Porcentagem de infecções de sítio cirúrgico do Hospital Universitário, no ano de 2016 e 2017.

Em relação a Pneumonia Associada a Ventilação (PAV) na UTI, conforme a Figura 3, no ano de 2016 evidencia-se que a Densidade de Incidência (DI) variou entre $12,9 \%$ no mês de fevereiro até $68,8 \%$ no mês de junho. Esta diferença expressiva se deve a redução do quadro de pessoal ocorrido no Serviço de Controle de Infecção Hospitalar (SCIH) em fevereiro/2016. Já entre os meses de agosto a dezembro, percebeu-se uma estabilidade nos valores, com dados variando de $54,6 \%$ a $49,2 \%$ (Figura 3). No referido período, o acompanhamento dos pacientes se deu de forma mais efetiva pelo aumento do quadro de pessoal e rediscussão do processo de classificação das infecções, facilitando o processo de trabalho e melhorando a qualidade das notificações.

Já em 2017 pode-se perceber que em abril houve um expressivo aumento da DI de PAV (Figura 3), aproximadamente 90\%. No referido mês, teve-se 188 pacientes em ventilação 
mecânica/dia e 17 casos de PAV. Provavelmente, esse aumento pode ter ocorrido devido ao acumulo de notificações referentes ao mês de março por falta de pessoal no setor, levando a viés desse aumento no referido mês. Nos meses subsequentes as taxas se mantiveram na faixa entre $47,8 \%$ a $23,1 \%$ (Figura 3 ). Os meses de junho e dezembro apresentaram os melhores índices, $23,1 \%$ e $29,0 \%$ respectivamente, devido a melhorias no processo de trabalho do setor.

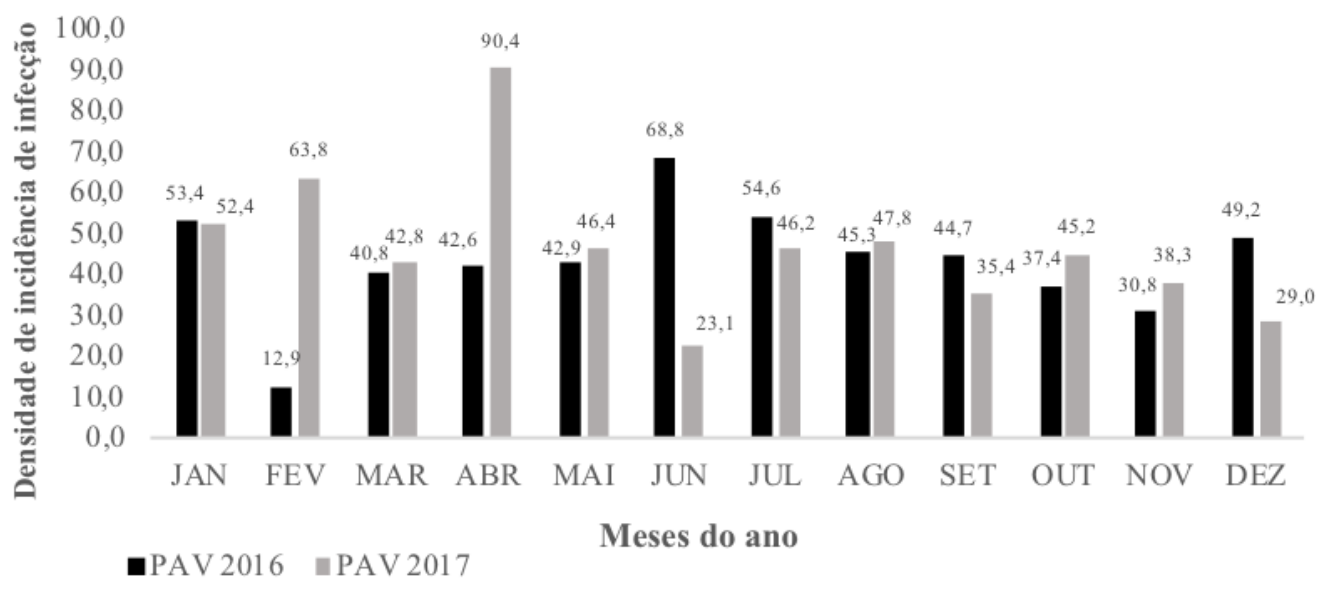

Figura 03- Densidade de incidência de infecção para PAV do Hospital Universitário, no ano de 2016 e 2017.

Em relação a ITU do Hospital Universitário, observa-se (Figura 04) que o mês de julho de 2016 apresentou o maior índice, com aproximadamente $33 \%$ de ITU/CV. Já os meses de novembro e dezembro evidenciaram menor DI, 7,1 \% em ambos os meses. Em 2017 pode-se observar uma DI de $6,1 \%$ no mês de março contra $28,3 \%$ no mês de julho. Os demais períodos ocorreram variação entre $8,3 \%$ a $26,8 \%$. Compreende-se a partir dos critérios de infecção para ITU que houve uma constante no ano de 2016 e 2017 relacionado ao uso do cateter e sua retirada precoce, favorecendo a diminuição das taxas de ITU no período.

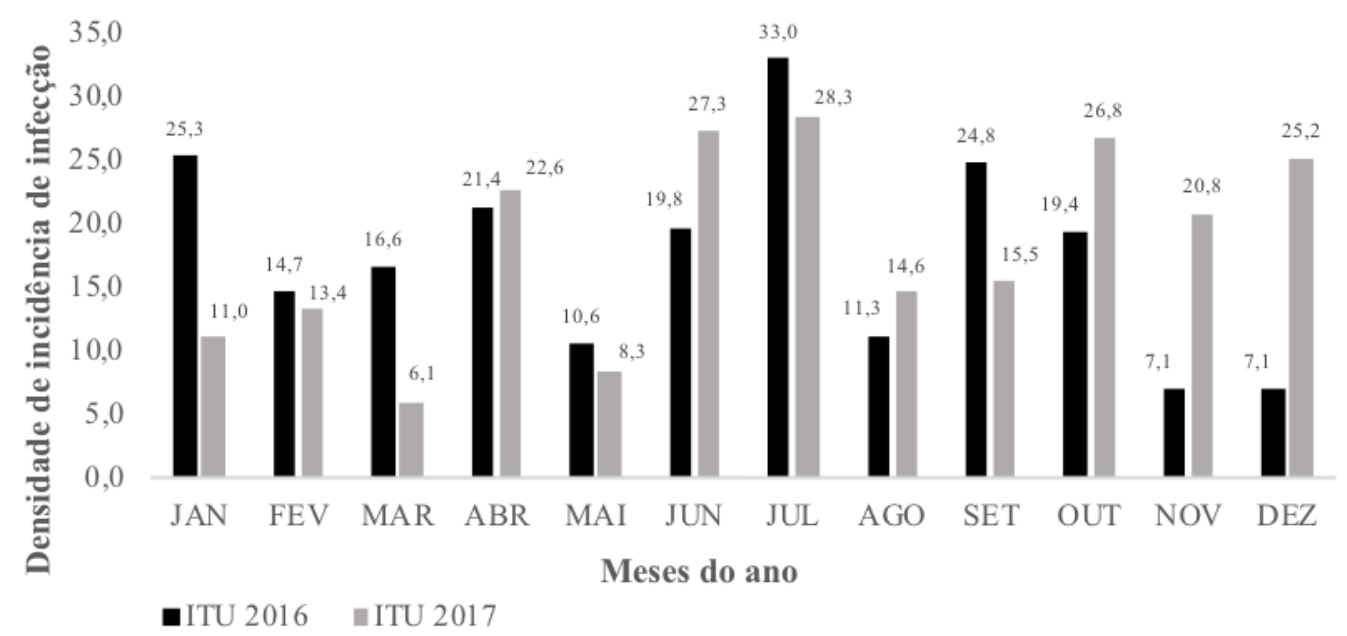

Figura 04- Densidade de incidência de infecção de ITU do Hospital Universitário, no ano de 2016 e 2017.

Para as IPCS da UTI do Hospital Universitário pode-se observar picos extremos nos meses de janeiro e dezembro de 2016 (Figura 5), com DI de $55,8 \%$ e $5,20 \%$ respectivamente. No 
entanto a Figura 6 é relativo à porcentagem de utilização desses dispositivos mostra uma variação discreta, com $64,1 \%$ em janeiro e $65,5 \%$ em dezembro. Ou seja, pode-se inferir que nos meses analisados, apesar das porcentagens de utilização dos Cateter Venoso Central (CVC) serem muito semelhantes no setor, no mês de janeiro/2016 os usuários expostos desenvolveram mais Infecções Primárias de Corrente Sanguínea Laboratorialmente confirmadas (IPCSL) do que os expostos em dezembro do mesmo ano.

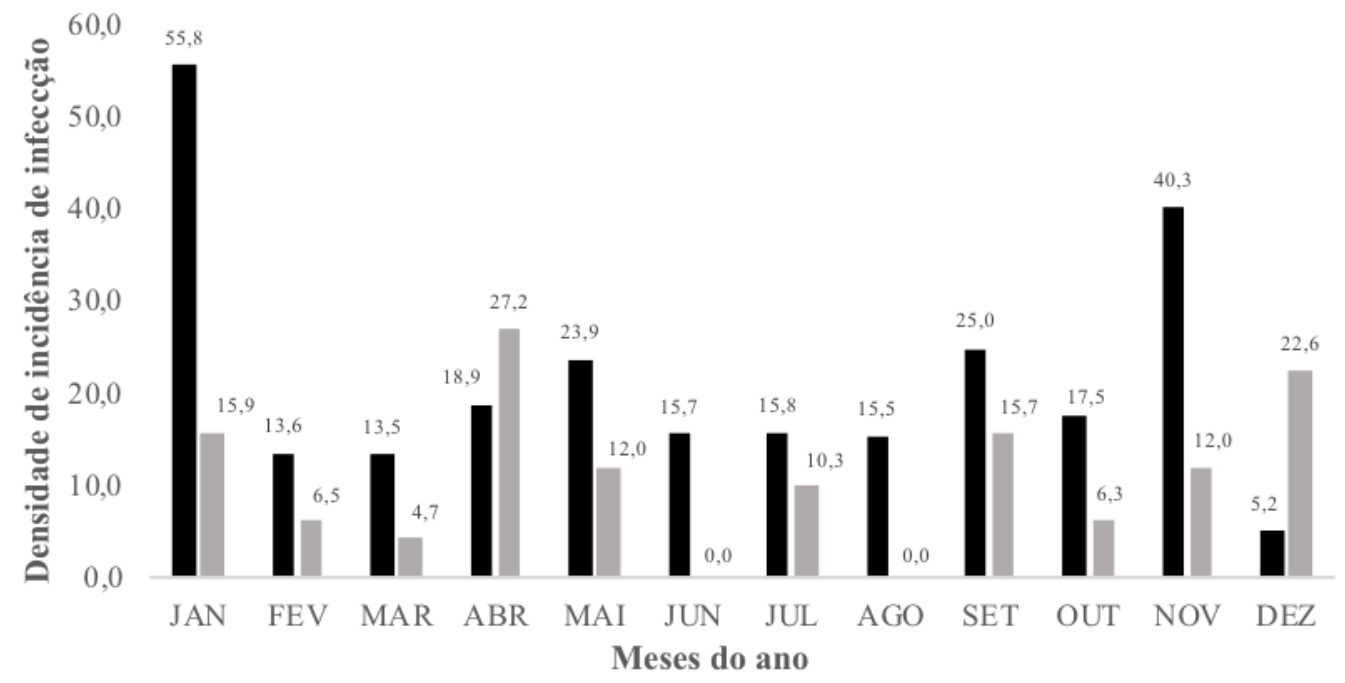

Figura 05- Densidade de incidência de IPCSL da UTI do Hospital Universitário, no ano de 2016 e 2017.

Em 2017 percebeu-se uma menor variabilidade da Densidade de Incidência (DI) da IPCSL ao longo do ano (Figura 5). O mês de abril apresentou o maior índice com $27,2 \%$ e porcentagem de utilização de $65 \%$ (Figura 6). Nos meses de junho e agosto não foram diagnosticados
IPCSL pelos critérios da ANVISA (provavelmente pela falta de realização de hemoculturas) e as porcentagem de utilização de CVC nestes meses foram de $52,7 \%$ e $57,5 \%$, respectivamente.

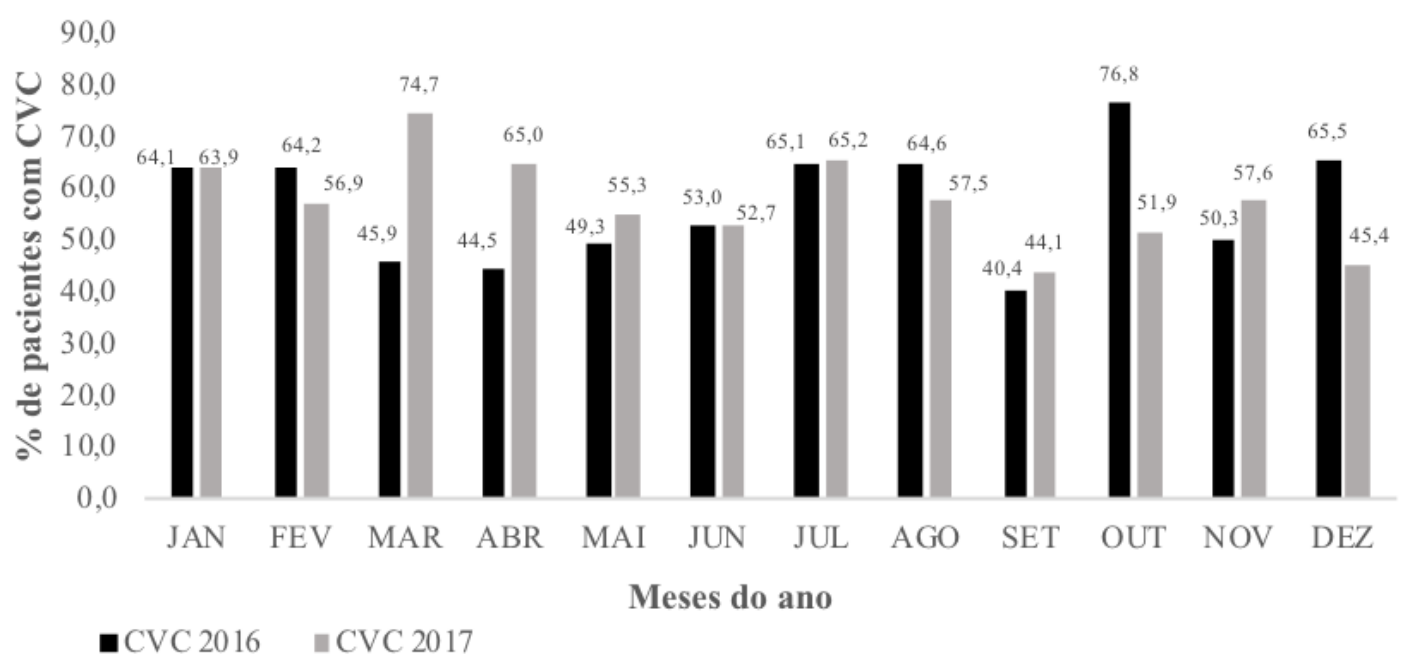

Figura 6- Porcentagem de pacientes com CVC da UTI do hospital Universitário, no ano de 2016 e 2017. 


\section{DISCUSSÃO}

Segundo a World Health Organization (WHO) ${ }^{15,16}$, a cada 100 pacientes hospitalizados, 7 em países desenvolvidos e 10 em países em desenvolvimento, adquirem a infecção durante o internamento. Considerado um grande e crescente problema de saúde pública no mundo. As IRAS's são responsáveis por um custo triplicado em comparação com clientes sem infecção e, mesmo diante de implementação de medidas para reduzir essa realidade, os índices dessa problemática permanecem altos no Brasil $(15,5 \%)$, o que corresponde a quase dois episódios de infecção por pessoa internada com IRAS nos hospitais brasileiros. Ademais, sabe-se que, as instituições de saúde pública possuem a maior taxa de prevalência de IRAS no país, correspondendo a aproximadamente $20 \%$, o que sobrecarrega o Sistema Único de Saúde, agravando este quadro. ${ }^{17,18}$

Em relação às infecções de sítio cirúrgico (ISC), sabe-se que esta infecção é o principal distúrbio que pode acometer o paciente cirúrgico e que é uma das principais infecções hospitalares no Brasil, ocupando a terceira posição entre todas as infecções em serviços de saúde e compreendendo um valor de $14 \%$ a $16 \%$ daquelas encontradas em pacientes hospitalizados. ${ }^{19}$ Trata-se da infecção relacionada ao cuidar que demanda maior custo às instituições e provoca o aumento significativo do número de complicações para a saúde pública em relação a realização de procedimentos cirúrgicos, sendo que $60 \%$ dos casos são passíveis de prevenção. ${ }^{20}$

As definições de procedimento cirúrgico, infecção e indicadores constituem a base que norteia o trabalho das Comissões de Controle de Infecção Hospitalar (CCIH). O paciente cirúrgico passível de vigilância epidemiológica de rotina é aquele submetido a um procedimento dentro do centro cirúrgico, que consista em pelo menos uma incisão e uma sutura, em regime de internação superior a 24 horas, excluindo-se procedimentos de debridamento cirúrgico, drenagem, episiotomia e biópsias que não envolvam vísceras ou cavidades. ${ }^{14}$

É importante salientar que as consequências das ISC incluem prejuízos físicos, emocionais e financeiros para os pacientes acometidos, além de custos excessivos e má reputação para as instituições envolvidas nessa assistência. Sendo assim, a fim de minimizar a ocorrência dessas infecções, devem ser empreendidos muitos esforços para prevenção, envolvendo pacientes, equipes profissionais e instituição. ${ }^{14}$

De maneira geral, analisando os dois anos pode-se perceber um controle das ISC, se considerada a média aceitável de 5\%. A utilização pela equipe de saúde das precauções padrão, os cuidados específicos em procedimentos cirúrgicos quanto a higienização das mãos, instrumental e outros, além da contribuição de acompanhantes e visitantes quanto aos cuidados em ambiente hospitalar pode ser reflexo desses resultados. Tal resultado também esteve presente em um trabalho realizado no Hospital das Clínicas da Universidade Federal de Pernambuco e no Real Hospital Português de Beneficência de Pernambuco, com 1593 pacientes submetidos a cirurgia bariátrica, os quais adotaram um conjunto de ações para controle das taxas de infecção, resultando em um índice final de $1 \%$ para ISC, considerado baixo e mostrando eficácia para as medidas implementadas. ${ }^{21}$

Segundo Almeida ${ }^{22}$ as Pneumonias Associada a Ventilação (PAV) é a infecção hospitalar mais prevalente nas UTIs e está associada à maior mortalidade, maior tempo de internação e maiores custos do cuidado do paciente. A vigilância da ocorrência de PAV fazse necessária para medir sua prevalência e avaliar as medidas de prevenção. Porém, vários estudos mostram que o diagnóstico de PAV é impreciso, passível de interpretação subjetiva e, muitas vezes, não corresponde aos achados histopatológicos de pneumonia.

Os dados epidemiológicos sobre a pneumonia relacionada a assistência à saúde nos hospitais brasileiros ainda são imprecisos. Já existem alguns dados sobre a temática, porém não são de cunho nacional. As publicações sobre está problemática tornaram-se obrigatórias a partir do ano de 2017. ${ }^{14}$

Dados do Estado de São Paulo publicados em 2015 mostraram que a média da densidade de incidência de PAV, foi de 9,87 casos por 1.000 dias de uso de ventilador em UTI adulto, sendo diferente para UTIs de hospital de ensino, com 13,40 casos por 1.000 ventilador-dia e UTIs de hospitais privados com 6,56 casos de PAV sendo que $41,17 \%$ dos pacientes da UTI adulto utilizavam VM. ${ }^{14}$ No presente trabalho, a PAV na UTI foi responsável por uma variação de 12,9\% para 49,2\% em 2016 e de $90 \%$ a 29,0\% em 2017. 
É importante salientar que as taxas de pneumonia associadas a ventilação mecânica PAV podem variar de acordo com a população de pacientes e os métodos diagnósticos disponíveis. Mas vários estudos demonstram que a incidência desta infecção aumenta com a duração da VM e apontam taxas de ataque de aproximadamente 3\% por dia durante os primeiros cinco dias de ventilação e depois $2 \%$ para cada dia subsequente. ${ }^{14}$

A mortalidade nos pacientes com PAV varia de 20 a $60 \%$. Estimativas da mortalidade atribuída a esta infecção variam nos diferentes estudos, mas aproximadamente $33 \%$ dos pacientes com PAV morrem em decorrência direta da doença. ${ }^{14}$

A Infecção do Trato Urinário (ITU) é uma das causas de infecções hospitalares de grande potencial preventivo pois está associada ao uso do cateter vesical de demora. ${ }^{14}$ Aproximadamente $10 \%$ dos pacientes internados são expostos ao cateterismo vesical. As infecções do trato urinário (ITU) representam cerca de $40 \%$ das infecções hospitalares e resulta em repercussão econômica, sequelas, complicações e danos imensuráveis à população. ${ }^{23}$ Foram observados no presente no trabalho, uma variação de ITU's de $33 \%$ a $7,1 \%$ em 2016 e de $6,1 \%$ a $26,8 \%$ no ano seguinte. Dessa forma, diversos estudos corroboram a necessidade da implementação de medidas preventivas criteriosas, como a avaliação diária da necessidade do cateter e descontinuação do mesmo antes do sétimo dia de uso. ${ }^{24}$

A problemática continua quando muitos pacientes permanecem com o dispositivo além do necessário, apesar das complicações infecciosas e não infecciosas (desconforto para o paciente, restrição da mobilidade, traumas uretrais por tração), inclusive custos hospitalares e prejuízos ao sistema de saúde público e privado. Entende-se que o tempo de permanência da cateterização vesical é o fator crucial para colonização e infecção (bacteriana e fúngica). ${ }^{14}$

A utilização do cateterismo vesical indiscriminado é uma prática que aumenta a DI das ITU/CV. Dessa forma, a equipe de saúde deve seguir critérios plausíveis para indicar a utilização desse procedimento e quando necessário, realizar os cuidados adequados evitando possíveis infecções e consequentemente as complicações advindas dessa prática.

Em relação às infecções da corrente sanguínea (ICS) associadas a cateteres centrais estão relacionadas a importantes desfechos desfavoráveis em saúde. Nos Estados Unidos (EUA) a mortalidade atribuível a esta síndrome varia bastante conforme os estudos, mas em geral, ultrapassa os $10 \%$, podendo chegar a $25 \%$ em alguns pacientes de maior risco. ${ }^{14}$

Dados da coorte do International Nosocomial Infection Control Consortium (INICC) que inclui 43 países em desenvolvimento apontam para mortalidade de cerca de $17 \%$. Em nosso país, o estudo Brazilian SCOPE (Surveillance and Control of Pathogens of Epidemiological Importance) apontou para $40 \%$ de mortalidade entre pacientes com ICS. ${ }^{14}$

A despeito do impacto enorme das ICS, esta é a infecção associada a cuidados em saúde de maior potencial preventivo que existe. De acordo com uma revisão sistemática recente, 65 a $70 \%$ dos casos poderiam ser prevenidos com adoção de medidas adequadas, como adesão aos bundles de boas práticas de inserção propostos pelo Institute of Healthcare Improvement (IHI) e a otimização das práticas de manutenção dos dispositivos. ${ }^{14}$

Estima-se que cerca de $60 \%$ das IRAS sejam associadas a algum dispositivo intravascular, levando a períodos prolongados de internação e elevado custo destinado à assistência, podendo atingir uma taxa de mortalidade de $69 \%{ }^{14,25,26}$

Entre amostras clínicas de hemoculturas, cerca de $40 \%$ dos isolados de Klebsiella spp. no Brasil já sejam resistentes aos carbapenêmicos. No caso do Acinetobacter spp., a resistência aos carbapenêmicos já é encontrada em quase $80 \%$ dos pacientes brasileiros com ICS por este agente. Além disto, ICS se associa ao prolongado tempo de internação hospitalar, prejudicando ainda mais nosso cenário nacional de falta de leitos. ${ }^{14,27}$

Sabe-se que, a infecção da corrente sanguínea associada à inserção e manutenção de cateter venoso central é uma das mais graves complicações, prolongando a internação e aumentando os custos da assistência médica. Portanto, medidas de controle da utilização indiscriminada desses dispositivos são essenciais para a redução dessa problemática e melhoria da qualidade da assistência oferecida aos pacientes.

De maneira geral, realizando um comparativo entre os anos de 2016 e 2017 percebeu-se uma redução significativa das IPCSL. Provavelmente, este resultado ocorreu por avanços nas medidas de controle de infecção 
relacionados a manutenção dos acessos centrais e tempo de permanência dos mesmos.

É importante salientar que, apesar das IPCSL serem favorecidas o seu aparecimento pelo uso do CVC, nem sempre suas causas estarão relacionadas a utilização deste dispositivo. Podendo acontecer a disseminação de um microorganismo a partir de outro foco.

\section{CONCLUSÃO}

Para as infecções hospitalares, a prevenção se torna a ferramenta essencial no combate a morbimortalidade relacionada a este quadro. Nesse sentido, a sensibilização da equipe de saúde, visitantes e familiares quanto as melhores práticas para o combate as infecções hospitalares são fundamentais para a redução dos índices das IRAS.

\section{REFERÊNCIAS}

1. Brasil. Portaria n 2.626 de 12 de maio de 1998. Expedir as diretrizes e normas para prevenção e o controle das infecções hospitalares. Diário Oficial da União - Brasília [Internet].1998 [citado 2020 Jan 20]. Disponível em: http://bvsms.saude.gov.br/bvs/saudelegis/gm/1998 /prt2616_12_05_1998.html.

2. Fernandes AT. Infecção hospitalar e suas interfaces na área da saúde. São Paulo: Atheneu, 2000.

3. Boyce JM. Environmental contamination makes na importante contributionto hospital infection. J. hosp. Infect. 2007; 65 (52): 50-54. https://doi.org/10.1016/S01956701(07)60015-2

4. Padoveze MC, Fortaleza CMCB. Infecções relacionadas à assistência à saúde: desafios para a saúde pública no Brasil. Rev. Saúde Pública. 2014; 48 (6): $\quad$ 995-1001. https://doi.org/10.1590/s00348910.201404800482 $\underline{5}$

5. Nogueira Junior C, Mello DS, Padoveze MC, Boszczowski I, Levin AS, Lacerda RA. Characterization of epidemiological surveillance systems for health care-associated infections (HAI) in the world and challenges for Brazil. Cad. Saúde Pública. 2014; 30 (1): 11-20. https://doi.org/10.1590/0102311X00044113

6. Catão RMR, Freitas e Silva PM, Feitosa RJP, Pimentel MC, Pereira HS. Prevalência de infecções hospitalares por Staphylococcus aureus e perfil de suscetibilidade aos antimicrobianos. Rev. enferm. UFPE on line. 2013; 7 (8): 557- 64. https://doi.org/10.5205/reuol.3452-28790-4ED.0708201325

7. Torres RA; Torres BR. Importância e bases de um programa de controle e prevenção de infecção em unidade de terapia intensiva geral. Rev. med. Minas Gerais (Online). 2015; 25 (4): 577-582. http://www.dx.doi.org/10.5935/22383182.201501 $\underline{25}$

8. Ferraz RRN, Lapchik MS, Barnabe AS, Fornari JV. Não conformidades nas práticas de precaução / Isolamento e ocorrência de infecções por acinetobacter baumanii relacionadas à assistência à saúde como elemento de melhoria no processo de gestão. RASM. 2014; 4 (1):19-29.

9. Oliveira FJG, Caetano JA, Silva VM, Almeida PC, Rodrigues AB, Siqueira JF. Use of clinical indicators in the evaluation of prevention and control practices for bloodstream infection. Texto \& contexto enferm. 2015; 24 (4): 1018-1026. https://doi.org/10.1590/010407072015000040400 14

10. HOECKE, F.V.; DELOOF, N. E.; CLAEYS, G. Performance evaluation of a modified chromogenic medium, Chrom ID MRSA New, for the detection of methicillin-resistant Staphylococcus aureus from clinical specimens. Eur. j. clin. microbiol. infect. dis. 2011; 30 (12): 1595-1598. https://doi.org/10.1007/s10096-011$\underline{1265-3}$

11. Qian Q, Venkataraman L, Kirby JE, Gold HS, Yamazumi T. Direct Detection of Methicillin Resistance in Staphylococcus aureus in Blood Culture Broth by use of a Penicillin Binding Protein 2a Latex Agglutination Test. J. Clin. Microbiol. 2010; 48 (140): 1420-1421. https://doi.org/10.1128/JCM.01517-09

12. Queenan AM, Bush K. Carbapenemases: the Versatile ß-Lactamases. Clin. Microbiol. Rev. 2007; $20 \quad$ (5): $\quad 440-458$. https://doi.org/10.1128/CMR.00001-07

13. Peirano G, Seki LM, Val Passos VL, Pinto MC, Guerra LR, Asensi MD. Carbapenemhydrolysing beta-lactamase KPC-2 in Klebsiella pneumoniae isolated in Rio de Janeiro, Brazil. J. antimicrob. Chemother. 2009; 63 (2); 265-268. http://www.dx.doi.org/10.1093/jac/dkn484

14. ANVISA. Agência Nacional de Vigilância Sanitária (Ministério da Saúde). Medidas de Prevenção de Infecção Relacionada à Assistência à Saúde. Brasília [Internet] 2013 e 2017 [citado 2020 Jan 20]. Disponível em: $<$ http://portal.anvisa.gov.br/documents/33852/271 $\underline{\text { 855/Medidas+de+Preven\%C3\%A7\%C3\%A3o+de }}$ 
+Infec $\% \mathrm{C} 3 \% \mathrm{~A} 7 \% \mathrm{C} 3 \% \mathrm{~A} 3 \mathrm{O}+$ Relacionada+\%C3\% A0+Assist \%C3\%AAncia+\%C3\%A0+Sa\%C3\%B Ade/6b16dab3-6d0c-4399-9d84-141d2e81c809. 15. WHO. World Health Organization. 10 facts on patient safety. [Internet] 2014 [citado 2020 Jan 20]. Disponível em: http://www.who.int/features/factfiles/patient_safet y/en/.

16. WHO, World Health Organization. Health care-associated infections Fact Sheet. [Internet] 2014 [citado 2020 Jan 20]. Disponível em: https://www.who.int/gpsc/country_work/gpsc_cci sc_fact_sheet_en.pdf.

17. Prade SS, Vasconcellos M M. Identificando Fontes de Dados nos Sistemas de Informações do SUS para a Vigilância Epidemiológica das Infecções Hospitalares. Inf. Epidemiol. Sus [Internet]. 2001;10 (3): 121128.https://doi.org/10.5123/S01041673200100 $\underline{0300003}$

18. Moura MEB, Campelo SMA, Brito FCP, Batista OMA, Araújo TME, Oliveira ADS. Infecção hospitalar: estudo de prevalência em um hospital público de ensino. Rev. bras. enferm. 2007; $60 \quad$ (4): $416-$ 421.https://doi.org/10.1590/S00347167200700040 $\underline{0011}$

19. ANVISA. Agência Nacional de Vigilância Sanitária. Sítio Cirúrgico: Critérios Nacionais de Infecções Relacionadas à Assistência à Saúde. Brasília [Internet]. 2009. Disponível em:http://www.anvisa.gov.br/servicosaude/manua is/criterios_nacionais_ISC.pdf

20. Carrara D, Strabelli TMV, Uip DE. Controle de infecção: a prática do terceiro milênio. Rio de Janeiro: Guanabara Koogan; 2017.

21. Ferraz ÁA, Bandeira VCFM, Santa-Cruz F, Aquino MAR, Buenos-Aires VG, Siqueira LT. Infecção de sítio cirúrgico após cirurgia bariátrica: resultados de uma abordagem com pacote de cuidados. Rev. Col. Bras. Cir. 2019;46(4):e2252. https://doi.org/10.1590/01006991e20192252
22. Almeida MCS. Avaliação dos eventos adversos associados à ventilação mecânica como indicador de qualidade assistencial. 2017. Tese (doutorado) -Faculdade de Medicina da Universidade de São Paulo, São Paulo, 2017. https://doi.org/10.11606/T.5.2018.tde15022018132230

23. Mazzo A, Godoy S, Alves LM, Mendes IAC, Trevizan MA, Rangel EML. Cateterismo urinário: facilidades e dificuldades relacionadas à sua padronização. Texto \& contexto enferm. 2011;20(2):333-339. https://doi.org/10.1590/S01040707201100020001 $\underline{6}$

24. Galiczewski JM; Shurpin KM. Na intervention to improve the catheter associated urinary tract infection rate in a medical intensive careunit: Direct observation of catheterinsertion procedure. Intensive CritCare Nurs. 2017; 40: 26-34. https://doi.org/10.1016/j.iccn.2016.12.003

25. Silva AG, Oliveira AC. Prevenção da infecção da corrente sanguínea relacionada ao cateter venoso central: uma revisão integrativa. Vigil. sanit. debate. 2016; 4 (2): 117-125. https://doi.org/10.3395/2317-269x.00705

26. Oliveira AC, Paula AO, Iquiapaza RA, Lacerda ACS. Healthcare associated infections and severity of illness index of patients in Intensive Care Units. Rev. Gaúch. enferm. 2012; 33(3):89-96.

https://doi.org/10.1590/S19831447201200030001 2

27. Mota FS, Oliveira HÁ, SOUTO RCF. Perfil e prevalência de resistência aos antimicrobianos de bactérias Gram-negativas isoladas de pacientes de uma unidade de terapia intensiva. RBAC. 2018;50(3):270-7. https://doi.org/10.21877/24483877.201800740 